\title{
Acidentes de motocicleta no município de Rio Branco: caracterização e tendências
}

\author{
Motorcycle accidents in the municipality of Rio Branco \\ in the State of Acre: characterization and trends
}

Greiciane da Silva Rocha ${ }^{1}$

Néia Schor ${ }^{2}$

${ }^{1}$ Centro de Ciências da Saúde e do Desporto (CCSD), Universidade Federal do Acre. BR 364 Km 04, Distrito Industrial. 69920-900 Rio Branco AC. greiciane.rocha@hotmail.com ${ }^{2}$ Faculdade de Saúde Pública, Universidade de São Paulo
Abstract The scope of this paper is to assess traffic accidents involving motorcycles, the victims involved and the increase in the fleet compared with other vehicles in Rio Branco, State of Acre. It is an epidemiological, descriptive and transversal study of accidents between 2005 and 2008 recorded by the Acre State Highway Department. There were 3,582 motorcycle accidents and 3,768 victims in the period. The motorcycle fleet increased by $72.8 \%$, with involvement in accidents increasing by $42.2 \%$, while accidents involving other vehicles only increased by $9.2 \%$. As regards victims, there is a predominance of men, with rates of 561.1, with the age groups of between 20 and 29 and 30 and 39 being the highest, with 755.4 and 542.2, respectively. With reference to accident characteristics, the highest number of accidents - 32.4\% - occurred in the afternoon, followed by the morning with 29.2\% and the evening with $28.9 \%$. 18.3\% occurred on Saturdays and $15.7 \%$ on Sundays. Collisions were the commonest kind of accident, with 3,036 (84.8\%) occurrences. The conclusion drawn is that it is essential to stage ongoing preventive programs and ensure greater integration among the institutions involved, with planning and campaigns to reverse the current situation.

Key words Traffic accidents, Victims of traffic accidents, Motorcycle accidents, Epidemiology, Work accident
Resumo O objetivo foi caracterizar os acidentes de trânsito com motocicleta, suas vítimas e o crescimento da frota, comparado-os às ocorrências com os demais tipos de veículo, em Rio Branco, Acre. Trata-se de um estudo, descritivo e transversal. Abrangeu os acidentes ocorridos entre 2005 e 2008 notificados pelo Departamento Estadual de Trânsito do Estado do Acre. No quadriênio foram observados 3.582 acidentes com motocicleta e 3.768 vítimas. A frota de motocicletas teve um crescimento de $72,8 \%$, com uma taxa de envolvimento em acidentes com um aumento de 42,2\%, enquanto os demais tipos de veículo tiveram uma elevação de apenas 9,2\%. Quanto às vítimas, há predominância do sexo masculino, os grupos etários de 20 a 29 e de 30 a 39 anos foram os de taxas mais elevadas. Quanto às características dos acidentes, o período da tarde destacou-se com 1.162 (32,4\%), seguido da manhã com $1.046(29,2 \%)$ e noite com 1.035 (28,9\%). O sábado se apresentou com 657 (18,3\%) e domingo com 563 (15,7\%). As colisões/abalroamento foram o tipo de acidente mais comum, com 3.036 (84,8\%) registros. São primordiais a efetivação contínua de programas preventivos e maior integralidade entre as instituições envolvidas, com planejamento e execuções, capazes de modificar o cenário atual.

Palavras-chaves Acidentes de Trânsito, Vitimas de acidentes de trânsito, Acidentes de motocicleta, Epidemiologia 


\section{Introdução}

Acidentes de transporte terrestre, aqui chamados de acidentes de trânsito, representam, em vários locais do mundo, a principal causa de morte não natural e uma realidade presente em muitos fragmentos sociais, apresentando-se como um grave problema de saúde pública. Segundo a Organização Mundial de Saúde (OMS), os acidentes de trânsito matam mais de um milhão de pessoas por ano em todo o mundo e deixam entre 20 e 50 milhões feridas, a maioria jovens, algumas com sequelas que levarão para o resto da vida. Como se não bastasse o custo desse imenso sofrimento, os países ainda perdem de um a dois por cento da sua riqueza com gastos relacionados a acidentes de trânsito ${ }^{1}$.

Ainda de acordo com a $\mathrm{OMS}^{2}$, em países da América do Sul, acidentes de tráfego vêm compondo inúmeros eventos agravantes para a saúde de uma população. Os Estados Unidos da América apresentaram, em 2005, uma taxa de mortalidade por acidente de trânsito de 29,7/ 100.000 hab., seguidos do Chile, com taxa 25,3/ 100.000 hab.; México, com 21,4/100.000 hab. e Argentina, com 17,1/100.000 hab. Em países europeus, a problemática não é muito diferente: a Alemanha apresenta taxa de 10,5/100.000 hab. e a Holanda, 8,4/100.000 hab. No continente Asiático, a taxa é de 13,7/100.000 hab.

Os acidentes de transporte são definidos pela OMS como todo acidente que envolva um veículo destinado ou usado no momento do acidente principalmente para o transporte de pessoas ou mercadorias de um lugar para outro. A Classificação Internacional de Doenças, em sua décima revisão (CID - 10/OMS) ${ }^{3}$, leva em conta o acidente de trânsito como aquele que envolve veículo transitando em via pública. Dentre as causas externas, os acidentes de trânsito destacam-se como importante grupo causal de óbito, levando ao aumento de "anos potenciais de vida perdidos" (APVP) em função do incremento de mortes de menores de idade e adultos jovens por tais causas. Além disso, custos diretos e indiretos com internação de vítimas acidentadas chegam a grandes proporções. Em uma pesquisa realizada na cidade de São Paulo, Mello Jorge e Koizumi ${ }^{5}$ destacaram um gasto acentuado com internações por causas externas em lesões decorrentes de acidentes de transporte.

As mesmas autoras, analisando dados do Sistema de Informações Hospitalares para o Brasil, verificaram que o gasto com internações por lesões relacionadas ao trânsito é mais elevado do que as hospitalizações por outros acidentes e violências e por aquelas decorrentes de causas naturais ${ }^{5}$.

Dentre os acidentes de transporte terrestre é elevado o número de acidentes envolvendo motociclistas. Estudos realizados no Sul do país ${ }^{6-8}$ apontam para alta frequência de ocorrências e uma elevada morbimortalidade no público masculino. No Brasil, ${ }^{9}$ a proporção chega a ser de 8,1 homens mortos para cada mulher entre as vítimas motociclistas.

Na Região Centro-Oeste ${ }^{10}$, no Distrito Federal a situação das motocicletas se confirma com um percentual crescente da mortalidade, passando de 25 casos em 1996 para 139 em 2007, ou seja, mais que o dobro, representando dessa forma, um incremento da problemática. Já em Goiânia ${ }^{11}$, os motociclistas foram os que mais se acidentaram em todos os dias da semana. Na grande Cuiabá $^{12}$, as motocicletas lideraram tendo uma prevalência de 39,6 de acidentes relacionados ao trabalho e 60,4 não relacionados. No Nordeste ${ }^{13}$, especificamente no estado de Pernambuco, foi observado um aumento dos acidentes com motociclistas, sobretudo em regiões do agreste e sertão.

Em se tratando da Região Sudeste ${ }^{14}$, a mortalidade teve destaque no Espírito Santo no ano de 2009, com uma taxa de 7,8 por 100.000 habitantes, seguido de São Paulo, com 3,6/100.000 hab.

Além da mortalidade, é significante a morbidade apresentada por esse tipo de vítima, o que pode ser observado nas unidades de emergência, com o crescente número de atendimentos a motociclistas com lesões de pele e fraturas ósseas ${ }^{15}$, tendo as regiões dos membros inferiores, seguidos dos superiores, como as mais afetadas ${ }^{16}$ ou vice-versa quando, membros superiores, seguidos dos inferiores ${ }^{17}$. Grande parte dos mecanismos de ação dos acidentes deve-se às colisões, que na avaliação da gravidade do trauma pela Abbreviated Injury Scale (AIS) leva o indivíduo a apresentar lesões de severidade máxima ${ }^{18}$.

É nesse contexto que os motociclistas vêm se apresentando como uma classe muito presente nas ocorrências de trânsito. Seu envolvimento deve-se, em parte, à sua alta vulnerabilidade, sobretudo em função das características de condução do veículo, sem dispor de qualquer estrutura metálica de proteção ${ }^{19}$, contando apenas com o dispositivo capacete.

Esse tem sido um dispositivo de proteção importante, em especial para a prevenção de sérias lesões cerebrais. Na Europa, particularmente na Itália, após a introdução da lei que rege o uso do capacete, foi notória a redução de admis- 
sões hospitalares para neurocirurgia, especificamente nos casos de lesão traumática cerebral ${ }^{20}$. Embora a adesão ao uso tenha melhorado em algumas cidades brasileiras, ainda é possível ver muitos indivíduos que não fazem uso de tal dispositivo, ou o utilizam de forma inadequada, com o mau acoplamento ao crânio e não ajuste da cinta jugular.

Em décadas anteriores, as motocicletas eram fundamentalmente um instrumento de lazer, mas nos dias atuais tornaram-se ferramenta de trabalho, o que se justifica pelo seu baixo custo, pelas inúmeras facilidades de aquisição e até mesmo em razão das eficientes estratégias de marketing que sugerem a possibilidade de se realizar diversas atividades em um menor tempo possível ${ }^{19}$.

Conforme Koizumi e Mello Jorge ${ }^{19}$, em alguns países, como os asiáticos, as vantagens que as motocicletas propiciam, como velocidade e facilidade no trânsito, acabaram por contribuir, deliberadamente, para seu incremento de consumo. Assim, antes de tudo, torna-se importante reconhecer o problema decorrente dos acidentes por esse tipo de veículo, no que diz respeito à sua magnitude, transcendência e tendências, abordando as várias facetas que ele comporta.

Diante disso, os objetivos deste estudo foram identificar o montante da frota de motocicletas/ automóveis e calcular a taxa de vítimas de acidentes de trânsito com motocicletas e automóveis para efeito de comparação, além de estabelecer o perfil dos motociclistas envolvidos em acidentes no município de Rio Branco, AC, Região Norte do território brasileiro, no período de 2005 a 2008 .

\section{Material e método}

Para alcançar os objetivos propostos, foi desenvolvido um estudo epidemiológico, de tipo descritivo e transversal. O interesse no desenvolvimento desta pesquisa foi conhecer e caracterizar os acidentes com motocicleta e traçar um perfil das vítimas motociclistas, no município de Rio Branco, capital do Estado do Acre, em especial quanto à utilização de dados secundários.

O estudo abrangeu a totalidade de acidentes com motocicletas no período de janeiro de 2005 a dezembro de 2008, ocorridos no Município, tendo como comparação o total de acidentes de trânsito e, em particular, os de automóvel. As taxas foram calculadas a partir da frequência absoluta de acidentes e vítimas anuais, respectivamente, dividido pela população anual. Todas as taxas foram multiplicadas por 100.000 , exceto a taxa de motorização, que foi obtida por 1.000 habitantes. Esta taxa foi levada em consideração, pois quanto maior o índice de motorização, maior a quantidade de pessoas que possuem veículos e, por conseguinte, maior a possibilidade de problemas decorrentes da circulação de veículos. $\mathrm{Na}$ frota de motocicletas foi incluído o número de motonetas, devido às características semelhantes entre tais veículos. Na população, para cada ano, foi utilizada como fonte o Instituto Brasileiro de Geografia e Estatística (IBGE): 2005(305.730), 2006(314.126), 2007(322.449) e 2008 (301.398), bem como sua estratificação por sexo e idade.

Antes da escolha das unidades de notificação e atendimento dos acidentes e vítimas do trânsito, foi feito um levantamento da existência de fichas de notificação, bem como das variáveis de interesse para o estudo proposto. A partir da análise dessas fichas, foi elaborada uma listagem das variáveis.

A fonte de dados foi representada pelo Detran/AC, devido ao fato dessa instituição ser responsável por todos os dados relativos às ocorrências de acidente de trânsito no Estado e no Município de Rio Branco, tanto em perímetro estadual quanto federal. Além disso, era a unidade que apresentava um maior número de registros notificados e atualizados. Os dados de mortalidade foram comparados com os registros de óbitos do Instituto Médico Legal, porém, com baixo êxito em virtude da ausência de informações, em especial quanto à classificação das vítimas do acidente como motociclistas.

As variáveis trabalhadas para o estudo em questão foram: momento da ocorrência do acidente (período do dia e dia da semana), natureza dos acidentes, magnitude dos acidentes, classificação da vítima quanto às categorias de sexo e idade e condição das vítimas (se óbito ou ferida). Devido a falhas na qualidade e cobertura das informações nos boletins de ocorrência de trânsito (BAT), não foi possível trabalhar com variáveis relevantes como uso do capacete no momento do acidente, habilitação para direção, velocidade do veículo, consumo de álcool, tipo de colisão, escolaridade e estado civil da vítima. Na variável vítima/ano, utilizou-se, para cada ano, a população específica por sexo e faixa etária.

Para formação do banco de dados da pesquisa com os registros do Detran/AC, após o período de coleta, as informações foram analisadas quanto à sua consistência e revisadas com o objetivo de evitar duplicidade de registros de 
vítimas. Após a coleta de dados, foi criado um Banco de Dados com uso do Software Epi-Info versão 6.0 para Windows e realizou-se o processamento e a tabulação de todos os dados. A análise destes baseou-se na estatística descritiva, com base na qual foram calculadas as frequências absolutas e relativas, e o cálculo de taxas.

O projeto de pesquisa foi apreciado e aprovado pelo Comitê de Ética em Pesquisa da Universidade Federal do Acre (UFAC) e da Faculdade de Saúde Pública da Universidade de São Paulo (FSP/USP), conforme preconiza a Resolução do Conselho Nacional de Saúde (CNS) 196/96²1.

\section{Resultados}

Quanto ao tamanho da frota, no Município de Rio Branco, verifica-se pela Tabela 1 um aumento expressivo no período analisado, com uma elevação de $47,8 \%$. A taxa de motorização, por sua vez, cresceu $49,8 \%$ no mesmo período (de 185,1 para 277,4 veículos para cada 1.000 habitantes).

Quanto aos tipos de veículos, comparando automóveis e motocicletas (incluindo motonetas), foi possível constatar que, em 2008, enquanto a proporção de automóveis era de $41 \%$, a de motocicletas era de $39,5 \%$, praticamente a mesma quantidade de automóveis licenciados. Entretanto, uma breve análise no tempo mostra que, em 2005, os automóveis representaram $44,2 \%$ de frota total e as motos, $33,7 \%$.

No quadriênio estudado (2005 - 2008), no município de Rio Branco - AC, foi observado que os acidentes com motocicleta apresentaram um número absoluto de 3.582 acidentes, com 3.768 vítimas. Os dados permitiram mostrar um percentual crescente de motociclistas envolvidos em acidentes, passando de 20,1\% em 2005 para 29,0\% em 2008.

Quando analisados os dados da Tabela 2, verifica-se que as taxas relativas a acidentes de motocicletas projetaram uma elevação de $42,2 \%$ ao passarem de 239,4 para 340,4 por 100.000 habitantes no período de 2005 a 2008. Em números absolutos, o crescimento foi de 294 ocorrências, correspondendo a um aumento de $40,2 \%$. No caso dos demais tipos de veículos, os registros indicaram uma redução de $9,2 \%$ na taxa de envolvimento em acidentes, podendo-se notar também que, em números absolutos, os mesmos tiveram uma mínima variação para menos no período.

Em relação à mensuração das vítimas de acidente por motocicletas e demais veículos, a Tabela 3 aponta para uma taxa crescente de vítimas

Tabela 1. Frota de veículos segundo tipo ( $\mathrm{N}$ e \%) e taxa de motorização por 1000 habitantes em Rio Branco/AC, 2005/2008.

\begin{tabular}{|c|c|c|c|c|}
\hline \multirow[b]{2}{*}{ Ano } & \multicolumn{3}{|c|}{ Tipo de veículo } & \multirow[b]{2}{*}{ Total } \\
\hline & Automóvel & Motocicleta & Outros & \\
\hline \multicolumn{5}{|l|}{2005} \\
\hline $\mathrm{N}$ & 25019 & 19093 & 12472 & 56584 \\
\hline$\%$ & 44,2 & 33,7 & 22,0 & 100 \\
\hline Taxa de motorização* & 81,8 & 62,5 & 40,8 & 185,1 \\
\hline \multicolumn{5}{|l|}{2006} \\
\hline $\mathrm{N}$ & 26843 & 22155 & 13219 & 62217 \\
\hline$\%$ & 43,1 & 35,6 & 21,3 & 100 \\
\hline Taxa de motorização* & 85,4 & 70,5 & 42,0 & 198,1 \\
\hline \multicolumn{5}{|l|}{2007} \\
\hline $\mathrm{N}$ & 30168 & 26539 & 14422 & 71129 \\
\hline$\%$ & 42,4 & 37,3 & 20,3 & 100 \\
\hline Taxa de motorização* & 93,6 & 82,3 & 44,7 & 220,6 \\
\hline \multicolumn{5}{|l|}{2008} \\
\hline $\mathrm{N}$ & 34274 & 32987 & 16353 & 83614 \\
\hline$\%$ & 41,0 & 39,5 & 19,6 & 100 \\
\hline Taxa de motorização & 113,7 & 109,4 & 54,2 & 277,4 \\
\hline
\end{tabular}

* Número de veículos/motocicletas e outros divididos pela população anual 2005(305.730); 2006 (314.126); 2007 (322.449) e 2008 (301.398). ${ }^{* *}$ Taxa de Motorização por 1000 habitantes é a relação entre o número de veículos existentes e um grupo de população (1000) residente, em um mesmo período. 
por motocicletas. Comparando-se os dados de 2005 e de 2008, torna-se patente uma proporção de aumento de 44,8\% nos números absolutos e de $46,8 \%$ nas taxas, passando de 248,3/100.000 hab. em 2005 para 364,6/100.000 hab. em 2008. Quanto aos demais veículos, os mesmos permaneceram com taxa em queda de 0,2 entre os anos 2005 e 2008. Porém, apresentou um decréscimo em números absolutos de 1,5\% no período.

A Tabela 4 apresenta características das vítimas em acidentes de trânsito com motocicletas. Quanto ao desfecho, foi observado que o percentual de óbitos passou de 20,3\% em 2005 para $38,0 \%$ em 2008, com uma redução de 8,9\% no ano de 2006. Em todo período analisado, constatou-se que houve um aumento de $87,2 \%$ nos óbitos, enquanto os lesionados tiveram um incremento de 44,3\%, passando de 20,1 em 2005 para 29,0 em 2008.

O sexo masculino teve uma maior taxa de envolvido nas ocorrências de acidentes com motocicletas, 561,1/100.000 hab. contra 57,2/100.000 hab. do sexo feminino. Em números relativos essa discrepância é mais expressiva, pois os homens representam $89,8 \%$ das vítimas, enquanto as mulheres somente $9,7 \%$.

Tabela 2. Acidentes de trânsito segundo tipo de veículo (N, \% e taxa por 100.000 habitantes), Rio Branco, AC 2005/2008.

\begin{tabular}{lrrr}
\hline & \multicolumn{2}{c}{ Tipo de veículo } & \\
\cline { 2 - 3 } Ano & Outros & Motocicleta & Total \\
\hline & & & \\
2005 & 755 & 732 & 1487 \\
$\mathrm{~N}$ & 50,7 & 49,2 & 100 \\
$\%$ & 246,9 & 239,4 & 486,3 \\
Taxa de acidente & & & \\
2006 & 724 & 792 & 1516 \\
$\mathrm{~N}$ & 47,8 & 52,2 & 100 \\
$\%$ & 230,5 & 252,1 & 483,1 \\
Taxa de acidente & & & \\
2007 & 723 & 1032 & 1755 \\
$\mathrm{~N}$ & 41,2 & 58,8 & 100 \\
$\%$ & 224,2 & 320,1 & 544,3 \\
Taxa de acidente & & & \\
2008 & 676 & 1026 & 1702 \\
$\mathrm{~N}$ & 39,7 & 60,3 & 100 \\
$\%$ & 224,3 & 340,4 & 564,7 \\
Taxa de acidente & & \\
\hline
\end{tabular}

* Taxa de acidente por tipo de veículo; número de veículo dividido pela população anual 2005(305.730); 2006 (314.126); 2007(322.449) e 2008 (301.398).
É relevante considerar que as faixas de 20 a 29 e de 30 a 39 anos possuem um maior risco de se envolver em acidentes, pois ao comparar o número de vítimas com a população dos respectivos grupos podemos perceber uma concentração maior de pessoas envolvidas. Porém, o grupo etário de maior evidencia em números absolutos foi o de 20 a 24 anos, pois apresentou 952 vítimas, correspondendo a $25,3 \%$ do total de vítimas no período, seguida do grupo de 25 a 29, com $24,3 \%$, e o de 30 a 34 , com $15,5 \%$.

Quanto às características dos acidentes, conforme a Tabela 5 a maior concentração se deu no período da tarde com 1162 ocorrências $(32,4 \%)$, seguido da manhã com 1046 (29,2\%) e noite com 1035 (28,9\%). O tipo de acidente predominante foi colisões/abalroamentos, com 3036 ocorrências $(84,8 \%)$. Em relação ao dia da semana, os sábados registraram 657 ocorrências $(18,3 \%)$, os domingos $563(15,7 \%)$ e sextas $536(15,0 \%)$. Os dias de menor ocorrência corresponderam às quartas e quintas-feiras, com $445(12,4 \%)$ e 453 $(12,6 \%)$ registros, respectivamente.

Tabela 3. Vítimas de acidentes de trânsito segundo tipo de veículo (N, \% e taxa por 100000 habitantes), Rio Branco/AC 2005/2008.

\begin{tabular}{lrrr}
\hline \multirow{2}{*}{ Ano } & \multicolumn{2}{c}{ Tipo de veículo } & \\
\cline { 2 - 3 } 2005 & Outros & Motocicleta & Total \\
\hline N & & & \\
$\%$ & 1219 & 759 & 1978 \\
Taxa de vítimas & 61,6 & 38,4 & 100 \\
2006 & 398,7 & 248,3 & 647,0 \\
N & & & \\
$\%$ & 1156 & 815 & 1971 \\
Taxa de vítimas & 58,7 & 41,4 & 100 \\
2007 & 368,0 & 259,5 & 627,5 \\
N & & & \\
$\%$ & 1299 & 1095 & 2394 \\
Taxa de vítimas & 54,3 & 45,7 & 100 \\
2008 & 402,9 & 339,6 & 742,4 \\
N & & & \\
$\%$ & 1201 & 1099 & 2300 \\
Taxa de vítimas & 398,5 & 364,6 & 763,1 \\
& & & \\
\hline
\end{tabular}

*Taxa de vítimas de acidente de trânsito por tipo de veículo; número de vítimas do tipo de veículo dividido pela população anual 2005(305.730); 2006 (314.126); 2007(322.449) e 2008 (301.398). 
Tabela 4. Características das vítimas motociclistas $(\mathrm{N}, \%$ e taxa de vítimas totais, de mortalidade e morbidade por 100000 habitantes $^{\star}$, Rio Branco/AC, 2005/2008.

\begin{tabular}{|c|c|c|c|c|c|c|c|c|c|}
\hline \multirow[b]{2}{*}{ Variáveis } & \multicolumn{9}{|c|}{ Total $(\mathrm{N}=3768)$} \\
\hline & $\mathbf{N}$ & $\%$ & $\begin{array}{c}\text { Taxa de } \\
\text { vítimas totais }\end{array}$ & Óbitos & $\%$ & $\begin{array}{c}\text { Taxa de } \\
\text { mortalidade }^{*}\end{array}$ & Lesionados & $\%$ & $\begin{array}{c}\text { Taxa de } \\
\text { morbidade }\end{array}$ \\
\hline \multicolumn{10}{|l|}{ Vítimas/Ano } \\
\hline 2005 & 759 & 20,1 & 248,3 & 16 & 20,3 & 5,2 & 743 & 20,1 & 243,0 \\
\hline 2006 & 815 & 21,6 & 259,5 & 7 & 8,9 & 2,2 & 808 & 21,9 & 257,2 \\
\hline 2007 & 1095 & 29,1 & 339,6 & 26 & 32,9 & 8,1 & 1069 & 29,0 & 331,5 \\
\hline 2008 & 1099 & 29,2 & 364,6 & 30 & 38,0 & 10,0 & 1069 & 29,0 & 354,7 \\
\hline \multicolumn{10}{|l|}{$\operatorname{Sexo}^{* *}$} \\
\hline Feminino & 366 & 9,7 & 57,2 & 3 & 3,8 & - & 363 & 9,8 & 56,7 \\
\hline Masculino & 3385 & 89,8 & 561,1 & 76 & 96,2 & 12,6 & 3309 & 89,7 & 548,5 \\
\hline NR & 17 & 0,5 & \# & - & - & \# & 17 & 0,5 & \# \\
\hline \multicolumn{10}{|l|}{ Faixa Etária ${ }^{* * *}$} \\
\hline 0 a 9 & - & - & \# & - & - & $\#$ & - & - & \# \\
\hline 10 a 19 & 188 & 5,0 & 69,8 & 6 & 7,6 & 2,2 & 182 & 4,9 & 67,5 \\
\hline 20 a 29 & 1868 & 49,5 & 755,4 & 38 & 48,0 & 15,4 & 1830 & 49,6 & 740,1 \\
\hline 30 a 39 & 982 & 26,1 & 542,2 & 19 & 24,1 & 10,5 & 963 & 26,1 & 531,8 \\
\hline 40 a 49 & 396 & 10,5 & 324,5 & 11 & 13,9 & 9,0 & 385 & 10,4 & 315,5 \\
\hline 50 a 59 & 94 & 2,5 & 131,5 & 1 & 1.3 & 1,4 & 93 & 2,5 & 130,1 \\
\hline 60 ou Mais & 75 & 2,0 & 106,7 & 1 & 1,3 & 1,4 & 74 & 2,0 & 105,3 \\
\hline $\mathrm{NR}^{* * * *}$ & 165 & 4,4 & \# & 3 & 3,8 & \# & 162 & 4,4 & \# \\
\hline
\end{tabular}

* Taxa de vítimas/mortalidade e morbidade obtida pelo número de vítimas total, óbitos e lesionados respectivamente pela população anual 2005(305.730); 2006 (314.126); 2007(322.449) e 2008 (301.398). ${ }^{* *}$ e ${ }^{* *}$ Taxa de vítimas totais, óbitos e lesionados obtidos pelo número de vítimas totais, óbitos e lesionados pela população por sexo e faixa etária. ${ }^{* * * *}$ NR: Não relatado. \# Sem cálculo de taxa.

\section{Discussão}

As motocicletas passaram a representar um modo específico de transporte, e hoje, acabam por traduzir uma originalidade, o perigoso prazer pela velocidade manifestada pela juventude ${ }^{22}$. Com o passar do tempo, as motos vêm ganhando espaço na circulação urbana, por serem uma opção mais econômica e por trazerem facilidades no tráfego e estacionamento ${ }^{6}$. No município de Rio Branco, tal situação se confirma, tanto que no período estudado sua frota sofreu um acréscimo considerável frente aos automóveis, $72,8 \%$ contra $37 \%$, respectivamente.

A esse respeito, estudo realizado em Itiuba, Bahia, por Luiz et al. ${ }^{23}$, relatou um crescente número de motocicletas em localidades rurais, onde $64 \%$ dos condutores eram lavradores e que esse aumento estaria vinculado ao baixo custo de aquisição e manutenção, facilitando, dessa forma, que pessoas de renda mais baixa tenham acesso a esse meio de transporte.

No território brasileiro, por volta de 1980, a motocicleta era considerada um instrumento de lazer. Na década de 1990, passou a ganhar mais espaço e a ser utilizada como instrumento de trabalho, na entrega de mercadorias, medicamentos, alimentos e outros, surgindo então os motoboys e mototaxistas ${ }^{6,23,24}$. Ferreira ${ }^{22}$ afirma que tais atividades se encontram em expansão, tanto de maneira formal quanto informal, gerando estatísticas de acidentes em uma realidade alheia à veracidade.

Essa situação se deveu ao desequilíbrio entre a menor oferta e maior procura de trabalho, exigência de alta qualificação profissional para muitas atividades laborais, entre outras. Contudo, surgiram atividades econômicas informais que passaram a incluir indivíduos sem perspectivas de trabalho, sendo esse um recurso para sua sobrevivência ${ }^{25}$.

Em Rio Branco, a situação é visível, sendo grande o número de indivíduos utilizando a moto como instrumento de trabalho informal, porém, na região, são poucas as pesquisas que retratam as ocorrências dos acidentes de trânsito envolvendo motociclistas. Das poucas existentes e analisadas, somente a de Lima et al. ${ }^{26}$, realizada no 
Tabela 5. Características dos acidentes de trânsito com motocicleta ( $\mathrm{N} \mathrm{e} \mathrm{\% ),} \mathrm{Rio} \mathrm{Branco/AC,} \mathrm{2005/}$ 2008.

\begin{tabular}{lrr}
\hline & \multicolumn{2}{c}{$\mathbf{N}=\mathbf{3 5 8 2}$} \\
\cline { 2 - 3 } \multicolumn{1}{c}{ Variáveis } & N & \% \\
\hline Turno do dia & & \\
Tarde & 1162 & 32,4 \\
Manhã & 1046 & 29,2 \\
Noite & 1035 & 28,9 \\
Madrugada & 308 & 8,6 \\
NR & 31 & 0,9 \\
Tipo de Acidente & & \\
Colisão / Abalroamento & 3036 & 84,7 \\
Choque com objeto Fixo & 153 & 4,3 \\
Atropelamento & 143 & 4,0 \\
Tombamento & 110 & 3,1 \\
Outros & 72 & 2,0 \\
Colisão com Animal & 33 & 0.9 \\
Queda & 32 & 0,9 \\
Saída da Pista & 2 & 0,1 \\
Não relatados & 1 & 0,0 \\
Dia da Semana & & \\
Sábado & 657 & 18,3 \\
Domingo & 563 & 15,7 \\
Sexta & 536 & 15,0 \\
Terça & 466 & 13,0 \\
Segunda & 462 & 12,9 \\
Quinta & 453 & 12,7 \\
Quarta & 445 & 12,4 \\
\hline & & \\
\hline & & \\
& &
\end{tabular}

período de 2001 a 2003, sobre a mortalidade por acidentes de trânsito, identificou que as motocicletas se apresentaram em último lugar entre os veículos envolvidos em acidentes de trânsito.

Já no estudo de Magalhães ${ }^{27}$, de base populacional e desenvolvido no Município de Rio Branco no período de 2007 a 2008, os dados corroboram nossos achados, uma vez que, em seus resultados, identificou-se um percentual elevado de envolvimento de indivíduos em acidentes de trânsito, tendo como tipo de veículo a motocicleta.

Em São Paulo, nas estatísticas elaboradas pela Companhia de Engenharia de Tráfego $(\mathrm{CET})^{28}$, as motocicletas se apresentam como o segundo tipo de veículo com maior envolvimento em acidentes com vítimas e em atropelamentos, pontuando que, desde muito tempo, o número de vítimas de acidentes de moto é elevado, sendo maior que o número de vítimas de acidentes provocados por automóveis, vitimando mais que os demais veículos. Tal situação se apresenta também no Distrito Fe- deral, onde estudo exploratório de série temporal mostrou que de 1996 a 2007 os óbitos de motociclistas passaram de 25 para 139, o que justifica a alta morbimortalidade apresentada ${ }^{10}$.

Outras investigações ${ }^{6,10,23,24,29-31}$ também abordam o maior envolvimento dos motociclistas em acidentes e os classificam como o principal tipo de vítima nas ocorrências, uma vez que eles apresentam ferimentos graves por absorverem toda a energia do impacto. Diante disso, ressalta-se, nesse aspecto, a importância dos equipamentos de segurança, como capacete e roupas adequadas.

Quanto às características das vítimas, trabalho desenvolvido por Andrade e Mello Jorge ${ }^{30}$ acentua a elevado número de lesionados, o que é apresentado também em outros estudos em que muitas das vítimas motociclistas precisam de atendimento de pronto-socorro e internação. Em outra pesquisa ${ }^{6}$ desenvolvida pelas mesmas autoras evidencia-se que, nos acidentes de transporte terrestre, é preciso ter em conta que muitas das vítimas são atendidas em serviços de emergência ou internadas, de modo que há um percentual pequeno de óbitos no local. Andrade e Mello Jorge ${ }^{6}$ e Soares e Barros ${ }^{32}$ referem que motociclistas, juntamente com ciclistas e pedestres, constituem o grupo que apresenta maior risco de internação.

Em relação aos desfechos (óbitos), é importante destacar o conceito de vítima fatal adotado pelo Detran/AC, que corresponde àquelas pessoas que foram a óbito no local de ocorrência do acidente ou, no máximo, até 30 dias após o evento traumático. Ou seja, deve ficar claro que os dados apresentados para essa distribuição não englobam as mortes acontecidas posteriormente.

Por sua vez, o Sistema de Informações de Informações Sobre Mortalidade (SIM), do Ministério da Saúde, ao adotar o conceito oferecido pela OMS, refere que a definição engloba as mortes ocorridas a qualquer tempo pós-evento, desde que a juízo do médico as lesões provocadas pelo acidente tenham sido responsáveis pela morte. Isto posto, destacamos que, neste trabalho, quando se faz referência a óbitos, o número diz respeito somente aos acontecidos no local do acidente, segundo o conceito do Denatran e não à totalidade das mortes, como preconizado pelo Ministério da Saúde.

Quanto à variável sexo e envolvimento nos acidentes de trânsito, estudos ${ }^{6,24,29,31,33-40}$ apontam para essa relação. Andrade e Mello Jorge ${ }^{6}$ relatam que encontraram pequena diferença entre os sexos de ocupantes de carro e pedestres. Já 
nas categorias de ciclistas e motociclistas, foi observada uma predominância do público masculino. As autoras ${ }^{6}$ assinalam o fato de condutores homens terem maior tendência a se tornarem vítimas, atribuindo isso a questões culturais, pelas quais dirigir um veículo, principalmente motocicleta, é, socialmente, da natureza masculina.

Relatos de motoboys (indivíduos de alta exposição e risco de se tornarem vítimas) indicam ainda como fatores relacionados aos acidentes: aspectos humanos, ambientais e mecânicos associados ao cansaço e à sobrecarga de tarefas, além de modos arriscados de dirigir, chuva, problemas nas vias, problemas na motocicleta, pressa e necessidade de concluir as atividades laborais ao fim do dia.

A participação dessa categoria nas ocorrências de trânsito está atribuída, muitas vezes, às regras instituídas por patrões para atender às normas do mercado, expondo motoboys a condições de risco e direcionando-os a uma escolha: correr risco ou ficar desempregado, norma adversa à instituída pela Legislação do País, principalmente ${ }^{41}$.

Outro trabalho ${ }^{42}$ relativo a motociclistas menciona, quanto à causa do acidente, que o comportamento de risco advém do condutor/ acidentado e que tal risco está relacionado, em geral, ao excesso de velocidade. Outros fatores listados foram a falta de atenção e o avanço do semáforo.

Em relação ao grupo etário, o estudo encontrou uma maior participação do grupo de adultos de 25 a 29 anos, seguido dos grupos de 20 a 24 anos e 30 a 39 anos. No tocante à frequência elevada de vítimas, na condição de motociclistas, vários autores ${ }^{6,29,34-36,39,43,44}$ relatam que adolescentes e adultos jovens, na idade de 10 a 39 anos, estão mais envolvidos nesse tipo de acidente.

Quanto às características do acidente, o estudo evidenciou maior ocorrência no período da tarde, seguido da noite. Os dias da semana de maior envolvimento foram sábado e domingo, ou seja, aos finais de semana. Algumas pesquisas $^{29,30,34}$ corroboram os achados deste trabalho, ao pontuar os fins de semana como os de maior incidência.

No tocante ao período do dia, pesquisas relatam o horário de 18 às 22 horas $^{35}$, como também o período da tarde seguido da noite ${ }^{31}$, o que pode ser explicado pelo cansaço ao final do dia e pelo grande fluxo de veículos ${ }^{30}$. Outro estudo ${ }^{31}$ aponta para alta gravidade de ocorrência no período noturno devido a fatores como a visibilidade, excesso de velocidade, desrespeito à sinalização, ingestão de bebidas alcoólicas e uso de drogas. Vale considerar ainda, as altas jornadas de trabalho sem interrupção, como importante fator associado à maior ocorrência de acidentes no período noturno ${ }^{45}$.

Quanto ao tipo de acidente, pode-se perceber que em Rio Branco as colisões representam o tipo mais comum de ocorrência. Oliveira e Sou$\mathrm{sa}^{8,24}$; Pordeus et al. ${ }^{42}$ também marcam para esse resultado, destacando as colisões seguidas das quedas nos acidentes envolvendo motociclistas.

\section{Considerações finais}

O estudo proposto foi realizado com o objetivo primordial de conhecer a realidade dos acidentes com motociclistas no Município de Rio Branco, em virtude da ausência de trabalhos dessa temática específica. Esse fato o diferencia de muitas outras pesquisas elaboradas acerca de acidentes de trânsito, devido a questões relacionadas ao momento da morte, como exposto.

Do ponto de vista metodológico, encontrouse uma limitação no que diz respeito à população total de vítimas fatais, devido à conceituação de vítima fatal adotada pelo Detran/AC. Para essa instituição, óbitos por acidentes de trânsito são entendidos, exclusivamente, como aqueles registrados no local de ocorrência do acidente ou até 30 dias após o evento traumático, desconsiderando por completo qualquer vítima que tenha falecido após esse período tendo como causa básica de morte o acidente de trânsito. Tal entendimento difere do que é preconizado pela OMS e adotado pelo Ministério da Saúde, que não estipula o prazo de até 30 dias para ocorrência de óbito, desde que sua causa básica tenha sido o AT.

Embora cientes dessa discrepância na definição dos óbitos, adotada pela Organização Mundial de Saúde, optou-se pela metodologia do Detran/AC em razão da insuficiência e da demora de alimentação no banco de informações do Sistema de Informação de Mortalidade do Ministério da Saúde. Contudo, o Detran/AC, mesmo com algumas falhas nos registros, era o que oferecia o maior número de notificações atualizadas até o período de 2008, ano limite de escolha para o estudo.

Vale considerar como um ponto importante, as dificuldades e as limitações de se trabalhar com dados secundários relacionados aos acidentes de transporte terrestre, em especial no tocante à mortalidade. As deficiências do sistema de informação e da atualização dessas fontes de dados estão associadas, em grande parte, com incompatibili- 
dade de dados da vítima em vários bancos, mau preenchimento de formulário, demora na alimentação dos bancos digitalizados, entre outros.

Assim, a implantação da técnica de Linkage de banco de dados na área dos acidentes de trânsito e de suas vítimas é vista como um desafio a ser enfrentado, e orienta a reflexão que muito possa ser feito pelo sistema de informação, e o quanto ele pode contribuir para avaliar as condições de saúde local, em especial as relacionadas à problemática dos acidentes de transporte terrestre. A integralização dos dados das inúmeras instituições envolvidas no trânsito é chave elementar para melhoria nas notificações das ocorrências, no planejamento local, subsidiando medidas de caráter preventivo e ainda contribuindo para a realização de estudos e pesquisas na área.

Diante da pesquisa realizada, cabem ainda algumas reflexões a serem disseminadas não só entre as instituições envolvidas com o trânsito, como também entre aquelas responsáveis pelo atendimento às vítimas motociclistas e, ainda, as que fazem o registro de sua mortalidade. Pensar sobre essa problemática requer relacioná-la com as atividades realizadas por esses indivíduos nas vias de circulação e em seu cotidiano.

Sem dúvida, deve-se reconhecer que vários fatores colaborativos possam estar engajados nesse contexto, não se tratando de tarefa de simples resolução. É essa complexidade que remete à necessidade de estudos mais aprofundados, segundo uma abordagem interdisciplinar, envolvendo profissionais de diferentes formações, instituições variadas para avaliação situacional e planejamento estratégico, com vistas à formula- ção e execução de ações capazes de modificar a situação atual.

É ponto importante a implementação de medidas, de curto e longo prazo, levando em conta aspectos relacionados ao usuário, equipamentos de segurança e até mesmo do veículo, às fiscalizações e punições às infrações. E, a longo prazo, há que se mencionar a educação de novos condutores e uma política contínua de fiscalização, lembrando que aspectos relativos ao controle de velocidade e uso de álcool ao dirigir, embora não tratados neste trabalho, são de extrema importância.

Outro ponto de nota é o crescimento alarmante do número de motocicletas frente ao de automóveis; não só como um instrumento de fácil acesso e pela efetividade nas conduções, a motos vêm ao longo do tempo, tornando-se uma verdadeira avalanche de problemas aos serviços de saúde. Ninguém poderia pensar que um veículo de condução individual iria se equiparar ao de condução coletiva como os automóveis; a pouca e nenhuma percepção de risco é que traz a tona a forte adesão às motocicletas, e aqui vale listar, o quanto são necessários trabalhos de prevenção voltados aos motociclistas, que devem ser introjetados desde a compra do veículo até o uso diário ao longo das vias públicas.

Além disso, é preciso lembrar que embora a maneira punitiva de multa pese no bolso do infrator, ela, sozinha, não é capaz de gerar mudança de hábitos nos condutores, visto que isso só será possível se for acompanhada de um conjunto de medidas efetivas, de caráter educativo e preventivo, com participação da sociedade civil e de setores governamentais.

\section{Colaboradores}

GS Rocha e N Schor participaram igualmente de todas as etapas de elaboração do artigo.

\section{Agradecimentos}

Ao Fundo de Desenvolvimento Científico e Tecnológico do Acre (FDCT), da Fundação de Tecnologia do Estado do Acre (Funtac) pelo financiamento da pesquisa. 


\section{Referências}

1. Organização Pan-Americana da Saúde (OPAS). Discurso de Horácio Toro: Dia Mundial da Saúde [internet]. 2004. [acessado $2007 \mathrm{fev}$ 8]. Disponível em: http://www.opas.org.br/mostrant.cfm?codigo dest $=209$.

2. Organização Mundial da Saúde (OMS). World health statistics annual. [base de dados na internet] 2005 [acessado 2009 abr 6]. Disponível em: http//www. who.int/whosis/database/mort/table_process.cfm

3. Organização Mundial da Saúde (OMS). Causas externas de morbidade e de mortalidade. In: Classificação estatística internacional de doenças e problemas relacionados à saúde. 10a Edição. São Paulo: OMS, EDUSP, USP; 2007. p. 969-1011.

4. Mello Jorge MHP, Latorre MR. Acidentes de trânsito no Brasil: dados e tendências. Cad Saude Publica 1994; 10(Supl. 1):S19-S44.

5. Mello Jorge MHP, Koizumi MS. Gastos governamentais do SUS com internações hospitalares por causa externas: análise no estado de São Paulo, 2000. Rev Bras Epidemiol 2004; 7(2):228-238.

6. Andrade SM, Mello Jorge MHP. Características das vítimas por acidentes de transporte terrestre em município da Região Sul do País. Rev Saude Publica 2000; 34(2):149-156.

7. Soares DFPP, Soares DA. Motociclistas vítimas de acidentes de trânsito em município da região Sul do Brasil. Acta Scientiarum Health Sciences 2003; 25(1):87-94

8. Oliveira NLB, Sousa RMC. Ocorrência de trânsito com motocicleta e sua relação com a mortalidade. Rev Latino-Am Enfermagem 2011; 19(2):1-8.

9. Reichenheim ME, Souza ER, Moraes CL, Mello Jorge MHP, Silva CMFP, Minayo MCS. Violence and injuries in Brazil: the effect, progress made, and challenges ahead. Lancet 2011; Series: 69-82.

10. Montenegro MMS, Duarte EC, Prado RC, Nascimento AF. Mortalidade de motociclistas em acidentes de transporte no Distrito Federal, 1996 a 2007. Rev Saude Publica 2011; 45(3):529-538.

11. Caixeta CR, Minamisava R, Oliveira LMAC, Brasil VV. Morbidade por acidente de transporte entre jovens de Goiânia, Goiás. Cien Saude Colet 2010; 15(4):2075-2084.

12. Soares BAC, Scatena JHG, Galvão ND. Acidentes e violências na Grande Cuiabá: o que retrata a demanda dos serviços de emergência. Epidemiol Serv Saúde 2009; 18(3):265-276.

13. Silva PHNV, Lima MLC, Moreira RS, Souza WV, Cabral APS. Estudo espacial da mortalidade por acidentes de motocicleta em Pernambuco. Rev Saude Publica 2011; 45(2):409-415.

14. MS/SVS/DASIS - Sistema de Informações sobre Mortalidade - SIM. Dados brutos. [base de dados na internet] 2009. [acessado $2012 \mathrm{fev} 7$ ]. Disponível em: http://tabnet.datasus.gov.br/cgi/deftohtm.exe? sim/cnv/ext10uf.def.

15. Oluwadiya KS, Oginni LM, Olasinde, Fadiora SO. Motorcycle limb injuries in a developing Country. WAJM 2004; 23(1):42-27.
16. Wilson SJ, Begg DJ, Samaranayaka A. Validity of using linked hospital and Police traffic crash records to analyse motorcycle injury crash characteristics. Accid Anal Prev 2012; 49:30-35.

17. Hefny AF, Barss P, Eid HO, Zidan FMA. Motorcycle-related injuries in the United Arab Emirates. Accid Anal Prev 2012; 49:245-248.

18. Langley JD, Begg DJ, Reeder AI. Motorcycle crashes resulting in death and hospitalisation. II: Traffic Crashes. Accid Anal Prev 1994; 26(2):165-171.

19. Koizumi MS, Mello Jorge MHP. Motos no trânsito brasileiro: do lazer à ferramenta de trabalho. Rev Abramet 2007; 25(2):12-21.

20. Brasil. Ministério da Saúde (MS). Conselho Nacional de Saúde. Resolução nº 196 de 10 de outubro de 1996. Diretrizes e Normas Regulamentadoras de Pesquisas Envolvendo Seres Humanos. Diário Oficial da União 1996; out 16.

21. Servadei F, Begliomini C, Gardini E, Giustini M, Taggi F, Kraus J. Effect of Italy's motorcycle helmet law on traumatic brain injuries. Injury Prev 2003; 9(3):257-260

22. Ferreira NS. Atividade de moto-frete e os riscos à saúde. Cad. Estud. e Pesq 2010; 24:87-96.

23. Luiz CM, Brito E, Gortado G, Júnior J, Tonha MC, Neto P. Perfil do condutor de motocicletas em zona rural do interior da Bahia. Rev Abramet 2009; 27(1): 22-29.

24. Oliveira NLB, Sousa RMC. Motociclistas frente às demais vítimas de acidentes de trânsito no município de Maringá. Acta Scientiarum Health Sciences 2004; 26(2):303-310.

25. Ganne N. Estudo sobre acidentes de trânsito envolvendo motocicletas na cidade de Corumbá e região, Estado do Mato Grosso do Sul, Brasil, no ano de 2007. Rev Amaz-Saúde 2010; 1(3):19-24.

26. Lima FM, Muniz BR, Lopes CM. Mortalidade por acidentes de trânsito em Rio Branco - Acre - Brasil, 2001 a 2003. Online Braz J Nurs [periódico na internet]. 2004 [acessado 2006 ago 3]. Disponível em: http://www.uff.br/nepae/objn303limaetal.htm.

27. Magalhães AF. Prevalência dos acidentes de trânsito auto-referidos em Rio Branco - Acre [dissertação]. Rio Branco: Universidade Federal do Acre; 2009.

28. Município de São Paulo. Companhia de Engenharia de Tráfego (CET). Fatos \& estatísticas de acidentes de trânsito de São Paulo. São Paulo: CET; 2000.

29. Bastos YGL, Andrade SM, Cordoni Júnior L. Acidentes de trânsito e o novo Código de Trânsito Brasileiro em cidade da Região Sul do Brasil. Inf Epidemiol SUS 1999; 8(2):37-45.

30. Andrade SM, Mello Jorge, MHP. Acidentes de transporte terrestre em cidade da Região Sul do Brasil: avaliação da cobertura e qualidade dos dados. Cad Saude Publica 2001; 17(6):1449-1456.

31. Bastos YGL, Andrade SM, Soares DA. Características dos acidentes de trânsito e das vítimas atendidas em serviço pré-hospitalar em cidade do sul do Brasil, 1997/2000. Cad Saude Publica 2005; 21(3):815-822. 
32. Soares DFP, Barros MBA. Fatores associados ao risco de internação por acidentes de trânsito no município de Maringá-PR. Rev Bras Epidemiol 2006; 9(2):193-205.

33. Marin L, Queiroz MS. A atualidade dos acidentes de trânsito na era da velocidade: uma visão geral. Cad Saude Publica 2000; 16(1):7-21.

34. Mello Jorge MHP, Gawryszewski VP, Latorre MR. Análise dos dados de mortalidade. Rev Saude Publica 1997; 31(4):5-25.

35. Barros AJD, Amaral RL, Oliveira MSB, Lima SC, Gonçalves EV. Acidentes de trânsito com vítimas: sub-registro, caracterização e letalidade. Cad Saude Publica 2003; 19(4):979-986.

36. Brito EM, Costa GR, Alves RS, Meneses EA, Duarte SC. Traumatismo crânio-encefálico em vítimas de acidentes de trânsito atendidas no Hospital de Base do Distrito Federal em 1994 e 1995. Rev Saúde de Dist Fed 1996; 7(3):41-49.

37. Klein CH. Mortes no trânsito do Rio de Janeiro, Brasil. Cad Saude Publica 1994; 10(Supl. 1):168-176.

38. Sallum AMC, Koizumi MS. Natureza e gravidade das lesões em vítimas de acidentes de trânsito de veículo a motor. Rev Esc Enferm 1999; 33(2):157-164.

39. Moskal A, Martin JL, Laumon B. Risk factors for injury accidents among moped and motorcycle riders. Accid Anal Prev 2010; 1-7.

40. Töró K, Hubay M, Sótonyi P, Keller E. Fatal traffic injuries among pedestrians, bicyclists and motor vehicle occupants. Forensic. Scienc International 2005; 151(2-3):151-156.

41. Veronese AM, Oliveira DLL. Os riscos dos acidentes de trânsito na perspectiva dos moto-boys: subsídios para a promoção da saúde. Cad Saude Publica 2006; 22(12):2717-2721.

42. Pordeus AMJ, Vieira LJES, Almeida PC, Andrade LM, Silva ACG, Lira SVG. Fatores associados à ocorrência do acidente de motocicleta na percepção do motociclista hospitalizado. Rev Bras Prom a Saúde 2010; 23(3):206-212.

43. Minayo MCS. A violência social sob a perspectiva da saúde pública. Cad Saude Publica 1994; 10(Supl. 1):7-18.

44. National Highway safety Administration. Department of transportation. Recent trends in fatal motorcycle crashes: An Update. Washington: National Center for Statistics and Analysis (NHTSA's); Department of transportation; 2006.[Technical Report]

45. Silva DW, Andrade SM, Soares DA, Nunes EFPA, Melchior R. Condições de trabalho e riscos no trânsito urbano na ótica de trabalhadores motociclistas. Physis 2008; 18(2):339-360.

Artigo apresentado em 12/03/2012

Aprovado em 22/04/2012

Versão final apresentada em 22/03/2012 
